who developed thrombocytopenia and in whom a lymphocyte transformation test to gold in vitro was positive. Probably a direct toxic mechanism was responsible for at least some of the adverse reactions to Myocrisin

We thank the Medical Research Council of New Zealand for financial support, and Karen Chaney, working under the supervision of Dr M Sears, for the IgE estimations.

1 Davis, P, et al, British Medical fournal, 1973, 3, 676

2 Hunder, G G, and Gleich, G J, Arthritis and Rheumatism, 1974, 17, 955.

3 Sears, M R, et al, 1979, submitted for publication.

- Ropes, M W, et al, Arthritis and Rheumatism, 1959, 2, 16.

(Accepted 24 September 1979)

Wellcome Medical Research Institute, Department of Medicine, University of Otago Medical School, Dunedin, New Zealand

D M GRENNAN, MD, PHD, senior lecturer in medicine

D G PALMER, MD, FRACP, associate professor of medicine

\section{Thrombosis of leg arteries after prolonged travel}

Venous thrombosis and subsequent pulmonary embolism after prolonged sedentary travel have been reported. ${ }^{1-3} \mathrm{We}$ describe three cases of thrombosis of leg arteries after prolonged travel.

\section{Case reports}

Case 1-A 68-year-old man presented with pain in his right calf similar to cramp after a flight lasting at least 20 hours from Australia to England. After arriving home his calf became more painful and the foot cold and numb. There was gradual improvement over the next few days, but seven days after arrival in England he sought hospital treatment. He was fit, blood pressure $140 / 80 \mathrm{~mm} \mathrm{Hg}$, in sinus rhythm, with no ankle oedema or calf tenderness. All pulses in the left leg were present and normal. The right common femoral pulse was present, but all pulses below this in the right leg were absent. There was reduced sensation in the right foot, which was cool. He had a block of his right superficial femoral artery. He was given intravenous heparin and subsequently warfarin. A right femoral arteriogram taken six days after admission (see figure) showed a complete block of his right superficial femoral artery, and there were signs of thrombosis. Interestingly there were multiple collateral channels suggesting

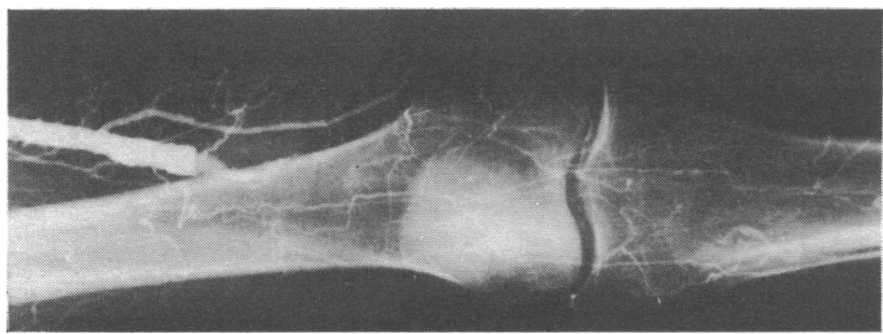

Case 1. Right femoral arteriogram showing a complete block of superficial femoral artery in region of adductor canal; presence of collateral vessels suggests pre-existing atheroma at this site. There is no filling of popliteal artery.

earlier arterial disease. There was no popliteal artery filling, though, lower down the calf there was filling of an attenuated posterior tibial artery. His leg remained viable and gradually improved. He was discharged after two weeks, though he experienced subsequent ischaemic symptoms.

Case 2-A 70-year-old woman was in excellent health until she arrived in Perth, Western Australia, in July 1978, after a flight from Great Britain On arrival her left leg was numb and she experienced cramp in her calf after walking about 50 yards. There was a delay of three weeks before referral to hospital, by which time her claudication distance was $300-400$ yards. Clinical examination showed classic signs of a left superficial femoral artery thrombosis. There were no signs of embolic disease. Because of her improved condition arteriography was not performed. She was advised to remain as mobile as possible on her return flight to Britain.

Case 3-A 44-year-old man underwent external iliac artery disobliteration in November 1977, which restored all leg and foot pulses. In February
1978 he undertook a five-day coach trip from Perth to Sydney, Australia, and found that he was unable to walk on arrival. He was referred in March 1978 on his return to Perth. Clinical examination failed to detect any pulses in his right leg. Arteriography and operation disclosed another thrombosis at the site of the disobliteration. Thrombectomy was performed. Subsequently all pulses were restored, and he was discharged well.

\section{Comment}

Two of these patients showed evidence of pre-existing arterial disease; in the third patient, this was not investigated. On long flights, such as those between Europe and Australia, patients with established peripheral arterial disease may benefit from being offered prophylaxis against arterial thrombosis as well as the more commonly recognised venous problems. Several factors, apart from being unable to walk about for many hours, may be concerned, particularly dehydration and excessive smoking that act by increasing blood viscosity and fibrinogen values. ${ }^{4}$

Thus travellers with peripheral arterial disease should be advised to remain as mobile and well hydrated as possible during prolonged travel. Sleeping tablets are probably contraindicated as these may exacerbate prolonged immobility and cause a concomitant fall in blood pressure. There may be a case for offering such patients aspirin or even low-dose heparin injections.

ADDENDUM-One of us (WMC) has been notified of a 68-year-old man who required an amputation below the left knee in Perth in July 1979 after arriving on the direct London-to-Perth flight. He had had a one-month history of left intermittent claudication.

${ }^{1}$ Beighton, P H, and Richards, P R, British Heart fournal, 1968, 30, 367. 2 Hawsley, S D, Smail, P J, and Thould, A K, British Medical fournal, $1975,4,276$.

${ }^{3}$ Symington, I S, and Stack, B H R, British fournal of Diseases of the Chest, 1977, 71, 138

4 Dintenfass, L, Medical fournal of Australia, 1975, 1, 617.

(Accepted 27 September 1979)

Canterbury and Thanet Health District

R E C COLLINS, FRCS, consultant surgeon

$S$ FIELD, MA, FRCR, consultant radiologist

University of Western Australia, Perth, Western Australia

W M CASTLEDEN, FRCS, FRACS, senior lecturer in surgery

\section{Disappearance of uraemic pruritus after lowering dialysate magnesium concentration}

Uraemic pruritus is well known in patients receiving chronic haemodialysis (CHD). Itching may be distressing and resistant to treatment. We report the case of a patient in whom all common treatments failed and whose pruritus completely disappeared after the concentration of magnesium in the dialysate was lowered.

\section{Case report}

A 59-year-old man with chronic glomerulonephritis had for two years been dialysed for six hours three times weekly with a $1.8 \mathrm{~m}^{2}$ capillary kidney against a dialysate bath containing $1.0 \mathrm{mmol} / \mathrm{l}(2.4 \mathrm{mg} / 100 \mathrm{ml})$ magnesium. He had had pruritus before starting CHD but it worsened afterwards. Although aluminium hydroxide $12 \mathrm{~g}$ /day was needed to control serum phosphorus concentration, parathyroid hormone was only slightly raised at $6.7 \mathrm{mU} / \mathrm{ml}$ (normal range $2-6 \mathrm{mU} / \mathrm{ml}$ ). Bone radiographs showed no uraemic osteopathy, so parathyroidectomy seemed not to be indicated. The itching, after briefly improving with antihistamine treatment, became worse. Ultraviolet phototherapy was tried without effect and was stopped after four weeks. Cholestyramine $4 \mathrm{~g}$ thrice daily also failed to give relief and was stopped after three weeks. We tried cimetidine, because it relieves pruritus in polycythaemia vera, ${ }^{1}$ but without success. Beginning in January 1979 we lowered the magnesium concentration in the dialysate from $1.0 \mathrm{mmol} / 1$ to $0.2 \mathrm{mmol} / \mathrm{l}(2.4 \mathrm{mg} / 100 \mathrm{ml}$ to $0.48 \mathrm{mg} / 100 \mathrm{ml})$. Consequently the serum magnesium concentration fell from $1.4 \mathrm{mmol} / \mathrm{l}(3.36 \mathrm{mg} / 100 \mathrm{ml})$ to a predialysis concentration of $0.57 \mathrm{mmol} / 1(1.36 \mathrm{mg} / 100 \mathrm{ml})$ and a postdialysis concentration of $0.37 \mathrm{mmol} / 1(0.88 \mathrm{mg} / 100 \mathrm{ml})$. After about a week the pruritus completely disappeared and had not relapsed after eight months. 


\section{Comment}

The cause of uraemic pruritus is unknown. In some cases it may be due to secondary hyperparathyroidism. Only in these patients is parathyroidectomy indicated. ${ }^{2}$ The mechanisms of other treatments such as ultraviolet light ${ }^{3}$ or cholestyramine ${ }^{4}$ are unknown and are effective in only some cases. In our patient the rapid and complete disappearance of pruritus after lowering the dialysate magnesium concentration suggests a causative relation between itching and serum magnesium concentration. Lowering the dialysate magnesium concentration is known to restore nerve conduction velocity towards normal in patients receiving $\mathrm{CHD},{ }^{5}$ and this could be the reason for the complete disappearance of the pruritus in our patient.

${ }^{1}$ Easton, P, and Galbraith, P R, New England fournal of Medicine, 1978, 299, 1134.

2 Massry, S G, et al, New England fournal of Medicine, 1968, 279, 697.

3 Gilchrest, B A, et al, New England fournal of Medicine, 1977, 297, 136.

4 Silverberg, D S, et al, British Medical fournal, 1977, 1, 752.

5 Stewart, W K, et al, Proceedings of the European Dialysis and Transplant Association, 1967, 4, 285.

(Accepted 19 September 1979)

Second Medical University Clinic, Vienna, Austria

HELMUT GRAF, MD, resident in nephrology

JOSEF KOVARIK, MD, resident in endocrinology

HANS K STUMMVOLL, MD, registrar in nephrology

AXEL WOLF, MD, registrar in nephrology

\section{A tube spacer to improve inhalation of drugs from pressurised aerosols}

Inhalation from pressurised aerosols provides an effective means of drug administration with a low incidence of side effects, but many patients cannot co-ordinate inhalation with aerosol actuation. ${ }^{1}$ Another potential disadvantage of pressurised aerosols is the deposition of drug on to the mucosa of the mouth and oropharynx caused by the high velocity of the flow of drug particles produced by aerosol actuation directly into the mouth. It has been shown, ${ }^{2}$ however, that the interposition of a tube spacer between the aerosol and the mouth reduces deposition of drug and also that the drug remains suspended in the system for several seconds, thus enabling inhalation to be delayed after aerosol actuation. This study was designed to test the hypothesis that a tube spacer could improve drug inhalation in patients unable to use aerosols efficiently.

\section{Patients, methods, and results}

Sixteen patients with chronic asthma (age range 62-77 years, 10 men) were studied. All had a forced expiratory volume in one second (FEV less than $70 \%$ of predicted normal, and the pretreatment $F_{E V}$ did not vary by more than $12.5 \%$ between study days. Each patient received four separate treatments on different days. All bronchodilator treatment was withheld for 12 hours before each test. The order of treatment was randomised. The four treatments were: (a) $500 \mu \mathrm{g}$ terbutaline from the conventional aerosol with actuation of aerosol at the beginning of inspiration; (b) $500 \mu \mathrm{g}$ terbutaline from a conventional aerosol with a spacer $10 \mathrm{~cm}$ long and $3.2 \mathrm{~cm}$ in diameter attached-inhalation and actuation were coordinated; (c) $500 \mu \mathrm{g}$ terbutaline from a conventional aerosol with a spacer $10 \mathrm{~cm}$ long and $3.2 \mathrm{~cm}$ in diameter attached-inhalation was delayed two seconds after actuation of aerosol; (d) $500 \mu \mathrm{g}$ terbutaline from a conventional aerosol-inhalation was delayed two seconds after actuation of aerosol. $\mathrm{FEV}_{1}$, forced vital capacity (FVC), peak expiratory flow rate (PEFR), and pulse rate were measured before and $5,10,20,30,60,120,180,240$, and 300 minutes after drug administration. Statistical analysis was carried out using a $t$ test for paired comparisons.

The mean maximum increases in FEV, FVC, and PEFR are shown in the table. All treatments produced significant improvements at five minutes and the values remained above pretreatment levels for up to five hours. The rates of onset and duration of effects were similar for all treatments. The mean maximum increases in FEV, FVC, and PEFR were consistently higher after the co-ordinated use of the conventional aerosol and were significantly greater than the mean maximum improvements produced by
Influence of tube spacer and co-ordination on airways response to inhaled terbutaline sulphate. Results are means of maximum improvement $( \pm S D)$, with statistical significance calculated as paired comparison to inhalation from aerosol co-ordinated

\begin{tabular}{|c|c|c|c|c|}
\hline & $\begin{array}{c}\text { Aerosol } \\
\text { co-ordinated }\end{array}$ & $\begin{array}{l}\text { Tube spacer } \\
\text { co-ordinated }\end{array}$ & $\begin{array}{l}\text { Tube spacer } \\
\text { uncoordinated }\end{array}$ & $\begin{array}{c}\text { Aerosol } \\
\text { uncoordinated }\end{array}$ \\
\hline $\begin{array}{l}\text { FEV }_{1}(\mathrm{ml}) \\
\text { FVC }(\mathrm{ml}) \\
\text { PEFR }(1 / \mathrm{min})\end{array}$ & $\begin{array}{c}346 \pm 180 \\
504 \div 309 \\
64 \pm 33\end{array}$ & $\begin{array}{c}325 \pm 171 \text { (NS) } \\
432 \pm 392 \text { (NS) } \\
58 \pm 38 \text { (NS) }\end{array}$ & $\begin{array}{c}319 \pm 173 \text { (NS) } \\
459 \pm 193 \text { (NS) } \\
46 \pm 37 \text { (NS) }\end{array}$ & $\begin{array}{cc}238 \pm 171 & (\mathrm{P}<0.02) \\
316 \pm 223 & (\mathrm{P}<0.05) \\
43 \pm 35 & (\mathrm{P}<0.05)\end{array}$ \\
\hline
\end{tabular}

NS $=$ Not Significant

the conventional aerosol uncoordinated. The mean maximum increases in the measurements of ventilatory function produced by the conventional aerosol used efficiently were not, however, significantly better than those after the use of the tube spacer co-ordinated or uncoordinated. The differences

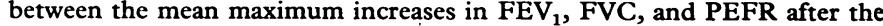
use of the tube spacer co-ordinated and the conventional aerosol uncoordinated were not significant.

\section{Comment}

Many patients with bronchial asthma cannot use inhalers efficiently. At worst they expire at the time of actuation or at best actuation is not co-ordinated with the beginning of inspiration. In this study we used a compromise for inefficient administration of an inhaler in that inspiration was delayed by two seconds after aerosol actuation and this caused a significant reduction in efficacy when compared with the co-ordinated use of the aerosol. Nevertheless, there was no significant difference between the improvements in ventilatory function produced by the tube spacer without co-ordination and those produced by the conventional aerosol co-ordinated, though the mean values were consistently lower for the spacer.

These results show that the tube spacer can at least partially compensate for the artificially poor inhalation technique used in this study and suggest that this device may have a useful role in clinical practice. If further clinical studies confirm this the tube spacer will provide a much needed alternative to the dry powder inhaler. ${ }^{3}$

${ }^{1}$ Paterson, I C, and Crompton, G K, British Medical fournal, 1976, 1, 76

2 Moren, F, International fournal of Pharmaceutics, 1978, 1, 205.

3 Hallworth, G W, British fournal of Clinical Pharmacology, 1971, 4, 689.

(Accepted 1 October 1979)

Respiratory Diseases Unit, Northern General Hospital, Edinburgh P BLOOMFIELD, MB, MRCP, research assistant

G K CROMPTON, MB, FRCPED, consultant physician

Astra Clinical Research Unit, Edinburgh

N J P WINSEY, BSC, PHD, clinical scientist

\section{Clostridium difficile-associated colitis after neomycin treated with metronidazole}

Clostridium difficile-associated colitis is being increasingly recognised after antibiotic treatment. The following case is the first to be documented after oral neomycin and was successfully treated with oral metronidazole.

\section{Case report}

A 65-year-old man with longstanding alcoholic cirrhosis was admitted with hepatic decompensation causing ascites and encephalopathy. Protein and salt restriction, oral lactulose, spironolactone, and neomycin ( $1 \mathrm{~g}$ four times daily) produced good improvement and he was discharged. Eight days after stopping neomycin he developed abdominal pain and bloody diarrhoea 8-10 times daily. This failed to settle over the next seven days, and on readmission he was dehydrated, febrile, and jaundiced but had no encephalopathy. Sigmoidoscopy showed grossly active colitis with ulceration, pus, and bleeding to the limit of examination, but there was no pseudomembrane. A stool sample was cultured in Reinforced Clostridial Medium with $0.2 \%$ paracresol ${ }^{1}$ and grew $\mathrm{Cl}$ difficile as identified morphologically and biochemic- 